\title{
Boundary shear distribution in channels with varying wall roughness
}

S. N. GHOSH

Dr D. W. Knight, Civil Engineering Department, University of Birmingham

The Author is to be congratulated on a useful paper that is of importance to every hydraulician engaged in flume experiments. Anyone working in the field of sediment transportation will have encountered the vexed problem of determining the appropriate bed shear velocity. It is surprising that the subject of non-uniform boundary shear distribution has attracted so little attention over the years, despite its fundamental importance and relevance to a number of open channel flow problems. The Author's experimental results are therefore most welcome.

34. The distribution of boundary shear stress over the wetted perimeter in open rectangular channels has been studied by a number of people; two important references are the work of Wagner ${ }^{14}$ and Goncharov. ${ }^{15}$ These represent studies in laminar and turbulent flow respectively. Goncharov's experimental results (chapter IV) have direct application to runs 16-20, in which the whole of the channel walls were of the same roughness but of different roughness from the channel bed. Since Goncharov has proposed equations defining the distribution of boundary shear stress, both with and without secondary flows, it is relevant to compare his results with those of the Author. A brief outline of his theoretical approach is given before comparing both sets of experimental results.

35. The logarithmic velocity distribution is assumed to be of the form

$$
\frac{u}{u_{\max }}=\frac{\ln [(y+c) / c]}{\ln [(Y+c) / c]}
$$

where $u$ is the velocity distance $y$ from the boundary, $Y$ is the depth of flow, $u_{\max }$ the surface velocity and $c$ a roughness coefficient $(=0.06 \Delta), \Delta$ being the height of the roughening excrescences. In terms of the mean velocity of flow $U$, equation (14) may be rewritten as

$$
\frac{u}{U}=\frac{\log [(16 \cdot 7 y+\Delta) / \Delta]}{\log (6 \cdot 15 Y / \Delta)}
$$

Using the notation given in Fig. 12, it follows that

$$
\frac{u_{\max }}{u_{y, B / 2}}=\frac{u_{\mathrm{Y}, z}}{u_{y, z}}
$$

where $u_{\max }$ is the maximum velocity, assumed to occur at the centre line of the free surface. Hence the velocity field is given by

$$
\frac{u_{y, z}}{u_{\max }}=\frac{\log \left(\frac{16 \cdot 7 y}{\Delta_{\mathrm{b}}}+1\right) \log \left(\frac{16 \cdot 7 z}{\Delta_{\mathrm{w}}}+1\right)}{\log \left(\frac{16 \cdot 7 Y}{\Delta_{\mathrm{b}}}\right) \log \left(\frac{16 \cdot 7 B}{2 \Delta_{\mathrm{w}}}\right)}
$$

where $\Delta_{\pi}$ and $\Delta_{\mathrm{b}}$ refer to the height of the roughening excrescences on the wall and bed respectively. Since

$$
Q=U B D=2 \int_{0}^{Y} \int_{0}^{B / 2} u_{y, z} \mathrm{~d} z \mathrm{~d} y
$$

Paper published : Proc. Instn Civ. Engrs, Part 2, 1972, 53, Dec., 529-544. 
Fig. 12. Notation

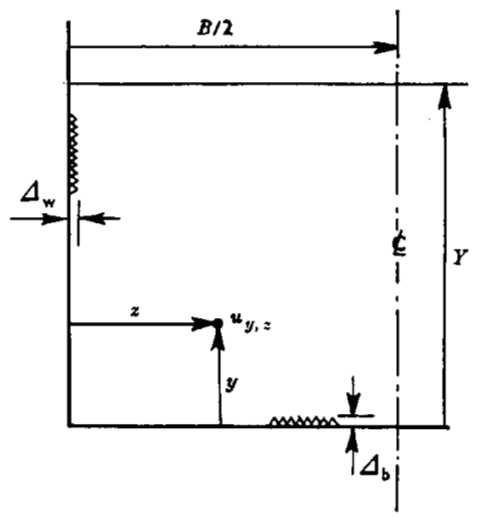

it follows that equation (16) may be expressed in terms of the mean velocity of flow rather than the maximum velocity. After integration the following theoretical velocity distribution is obtained

$$
\frac{u_{y, z}}{U}=\frac{\log \left(\frac{16 \cdot 7 y}{\Delta_{\mathrm{b}}}+1\right) \log \left(\frac{16 \cdot 7_{z}}{\Delta_{\mathrm{w}}}+1\right)}{\log \left(\frac{6 \cdot 15 Y}{\Delta_{\mathrm{b}}}\right) \log \left(\frac{6 \cdot 15 B}{2 \Delta_{\mathrm{w}}}\right)} \quad . \quad . .
$$

36. The boundary shear stress at any point on the wetted perimeter is then obtained by considering the velocity distribution normal to any point on the boundary. For example, for the walls, using the maximum local velocity along the vertical at the centre line yields the expression

$$
\Upsilon_{\text {ow }}=\frac{0.33 \rho g\left[\ln \left(\frac{y+c_{\mathrm{b}}}{c_{\mathrm{b}}}\right)\right]^{2}}{\left[\ln \left(\frac{B}{2 \times 2 \cdot 7 c_{\mathrm{w}}}\right) \ln \left(\frac{Y}{2 \cdot 7 c_{\mathrm{b}}}\right)\right]^{2}} \frac{U^{2}}{2 g}
$$

Hence the theoretical distribution of shear stress on the walls is

$$
\mathrm{\Upsilon}_{\mathrm{ow}}=\frac{0.06205 \rho g\left[\log \left(\frac{16 \cdot 7 y}{\Delta_{\mathrm{b}}}+1\right)\right]^{2}}{\left[\log \left(\frac{6 \cdot 15 B}{2 \Delta_{\mathrm{w}}}\right) \log \left(\frac{6 \cdot 15 Y}{\Delta_{\mathrm{b}}}\right)\right]^{2}} \frac{U^{2}}{2 g}
$$

Similarly, the theoretical distribution of shear stress on the bed is

$$
\Upsilon_{\mathrm{ob}}=\frac{0.06205 \rho g\left[\log \left(\frac{16 \cdot 7 z}{\Delta_{\mathrm{w}}}+1\right)\right]^{2}}{\left[\log \left(\frac{6 \cdot 15 B}{2 \Delta_{\mathrm{w}}}\right) \log \left(\frac{6 \cdot 15 Y}{\Delta_{\mathrm{b}}}\right)\right]^{2}} \frac{U^{2}}{2 g}
$$

37. Equations (17)-(19) effectively solve the problem provided that the assumptions about the maximum velocity occurring at the free surface and the logarithmic velocity distribution are valid.

38. In order to apply equations (17)-(19), appropriate values for $\Delta_{\mathrm{w}}$ and $\Delta_{\mathrm{b}}$ are required. Using Goncharov's relationship between $\Delta_{\mathrm{w}}$ and Reynolds number for a smooth boundary, a mean value for $\Delta_{\mathrm{w}}$ of $0.15 \mathrm{~mm}$ was obtained. The value of $\Delta_{\mathrm{b}}$ was taken to be $3.17 \mathrm{~mm}(=0.125 \mathrm{in}$., size of Author's spheres). The value for $\Delta_{w}$ compares with a value of $0.17 \mathrm{~mm}$ used in Goncharov's experiments. 
39. The theoretical boundary shear stresses for runs $16-20$ as given by equations (18) and (19) at different points along the channel wall and bed are shown in Tables 2 and 3 and plotted in Figs 13-17. The experimental results for Fig. 6 are also shown for comparison. Theoretical isovels are also shown in Figs 13-17 at values corresponding to those shown in Fig. 4.

40. A comparison of the velocity distribution given in Figs 13-17 with those given in Fig. 4 strongly suggests the presence of secondary flows. An indication of the pattern of secondary flow is given in Fig. 13, together with the necessary adjustment of the isovels. A measure of the three dimensionality of the flow may be given by the depression of the maximum velocity below the free surface.

41. Goncharov's results suggested the empirical equation

$$
\frac{y^{\prime}}{Y}=1 \cdot 13 \sqrt[3]{ } /\left[\frac{B}{Y} \sqrt{ } /\left(\frac{\Delta_{\mathrm{b}}}{Y}\right)\right]
$$

where $y^{\prime}$ is the height from the bed to the position of maximum velocity. Equation (20) is valid in the range $0.4<y^{\prime} / Y<1 \cdot 0$. It should be noted that for all values of the right-hand side exceeding unity, the height $y^{\prime}$ is assumed to be equal to $Y$. The consequent increase in bottom shear stress due to secondary flows is then given by

$$
\frac{\Upsilon_{\mathrm{ob}}^{\prime}}{\mathrm{\Upsilon}_{\mathrm{ob}}}=\sqrt[3]{\left[\frac{Y}{y^{\prime}}\right]}
$$

where $\Upsilon^{\prime}{ }_{\text {ob }}$ is the corrected shear stress.

42. Values of $y^{\prime} / Y$ and $\Upsilon_{o b}^{\prime} / Y_{o b}$ are shown in Table 4, together with the experimental values of $y^{\prime} / Y$ obtained from Fig. 4. The three-dimensionality of the flow

\begin{tabular}{|c|c|c|c|c|c|c|c|}
\hline \multirow{2}{*}{ Run } & \multirow{2}{*}{$\begin{array}{c}\text { Depth } \\
Y, m\end{array}$} & \multicolumn{2}{|c|}{$y=Y$} & \multicolumn{2}{|c|}{$y=Y / 2$} & \multicolumn{2}{|c|}{$y=\Delta_{b}$} \\
\hline & & $\begin{array}{c}\text { Theoreti- } \\
\text { cal } \\
\Upsilon_{\text {ow }}\end{array}$ & $\begin{array}{l}\text { Experi- } \\
\Upsilon_{\text {mental }}\end{array}$ & $\begin{array}{c}\text { Theoreti- } \\
\text { cal } \\
\Upsilon_{\text {ow }}\end{array}$ & $\underset{\Upsilon_{\text {ow }}}{\text { Experi- }}$ & $\begin{array}{c}\text { Theoreti- } \\
\text { cal } \\
\Upsilon_{\text {ow }}\end{array}$ & $\begin{array}{l}\text { Experi- } \\
\underbrace{}_{\text {mental }}\end{array}$ \\
\hline $\begin{array}{l}16 \\
17 \\
18 \\
19 \\
20\end{array}$ & $\begin{array}{l}0.340 \\
0.373 \\
0.423 \\
0.465 \\
0.510\end{array}$ & $\begin{array}{l}0.029 \\
0.037 \\
0.039 \\
0.044 \\
0.050\end{array}$ & $\begin{array}{l}0.035 \\
0.035 \\
0.041 \\
0.039 \\
0.036\end{array}$ & $\begin{array}{l}0.023 \\
0.029 \\
0.031 \\
0.035 \\
0.040\end{array}$ & $\begin{array}{l}0.019 \\
0.019 \\
0.020 \\
0.026 \\
0.033\end{array}$ & $\begin{array}{l}0.006 \\
0.007 \\
0.007 \\
0.008 \\
0.009\end{array}$ & $\begin{array}{l}0.006 \\
0.005 \\
0.004 \\
0.004 \\
0.012\end{array}$ \\
\hline
\end{tabular}

Table 2. Boundary shear stresses for walls in $\mathrm{lb} / \mathrm{ft}$

Table 3. Boundary shear stresses for bed in $\mathrm{lb} / \mathrm{sq}$. $\mathrm{ft}\left(\mathrm{Y}^{\prime}{ }_{\text {ob }}\right.$ value includes secondary

\begin{tabular}{|c|c|c|c|c|c|c|c|c|c|c|}
\hline \multirow{3}{*}{ Run } & \multirow{3}{*}{$\begin{array}{c}\text { Depth } \\
Y, m\end{array}$} & \multicolumn{3}{|c|}{$z=B / 2$} & \multicolumn{3}{|c|}{$z=B / 4$} & \multicolumn{3}{|c|}{$z=\Delta_{\mathrm{w}}$} \\
\hline & & \multicolumn{2}{|c|}{ Theoretical } & \multirow{2}{*}{$\begin{array}{l}\text { Experi- } \\
\Upsilon_{\Upsilon_{o b}}\end{array}$} & \multicolumn{2}{|c|}{ Theoretical } & \multirow{2}{*}{$\begin{array}{l}\text { Experi- } \\
\text { mental } \\
\Upsilon_{o b}\end{array}$} & \multicolumn{2}{|c|}{ Theoretical } & \multirow{2}{*}{$\begin{array}{l}\text { Experi- } \\
\text { mental } \\
\Upsilon_{\text {ob }}\end{array}$} \\
\hline & & $\mathbf{r}_{\mathrm{ob}}$ & $\Upsilon^{\prime \prime}{ }_{o b}$ & & $\Upsilon_{\mathrm{ob}}$ & $Y^{\prime}{ }_{a b}$ & & $\Upsilon_{\mathrm{ob}}$ & $\Upsilon^{\prime}{ }_{b b}$ & \\
\hline $\begin{array}{l}16 \\
17 \\
18 \\
19 \\
20\end{array}$ & $\begin{array}{l}0.340 \\
0.373 \\
0.423 \\
0.465 \\
0.510\end{array}$ & $\begin{array}{l}0.066 \\
0.080 \\
0.082 \\
0.090 \\
0.099\end{array}$ & $\begin{array}{l}0.071 \\
0.088 \\
0.092 \\
0.103 \\
0.114\end{array}$ & $\begin{array}{l}0.080 \\
0.084 \\
0.094 \\
0.100 \\
0.112\end{array}$ & $\begin{array}{l}0.056 \\
0.069 \\
0.070 \\
0.077 \\
0.085\end{array}$ & $\begin{array}{l}0.061 \\
0.075 \\
0.079 \\
0.089 \\
0.098\end{array}$ & $\begin{array}{l}0.061 \\
0.061 \\
0.070 \\
0.067 \\
0.080\end{array}$ & $\begin{array}{l}0.006 \\
0.007 \\
0.007 \\
0.008 \\
0.009\end{array}$ & $\begin{array}{l}0.007 \\
0.008 \\
0.008 \\
0.009 \\
0.010\end{array}$ & $\begin{array}{l}0.006 \\
0.006 \\
0.005 \\
0.005 \\
0.005\end{array}$ \\
\hline
\end{tabular}
flow effects) 


\section{DISCUSSION}
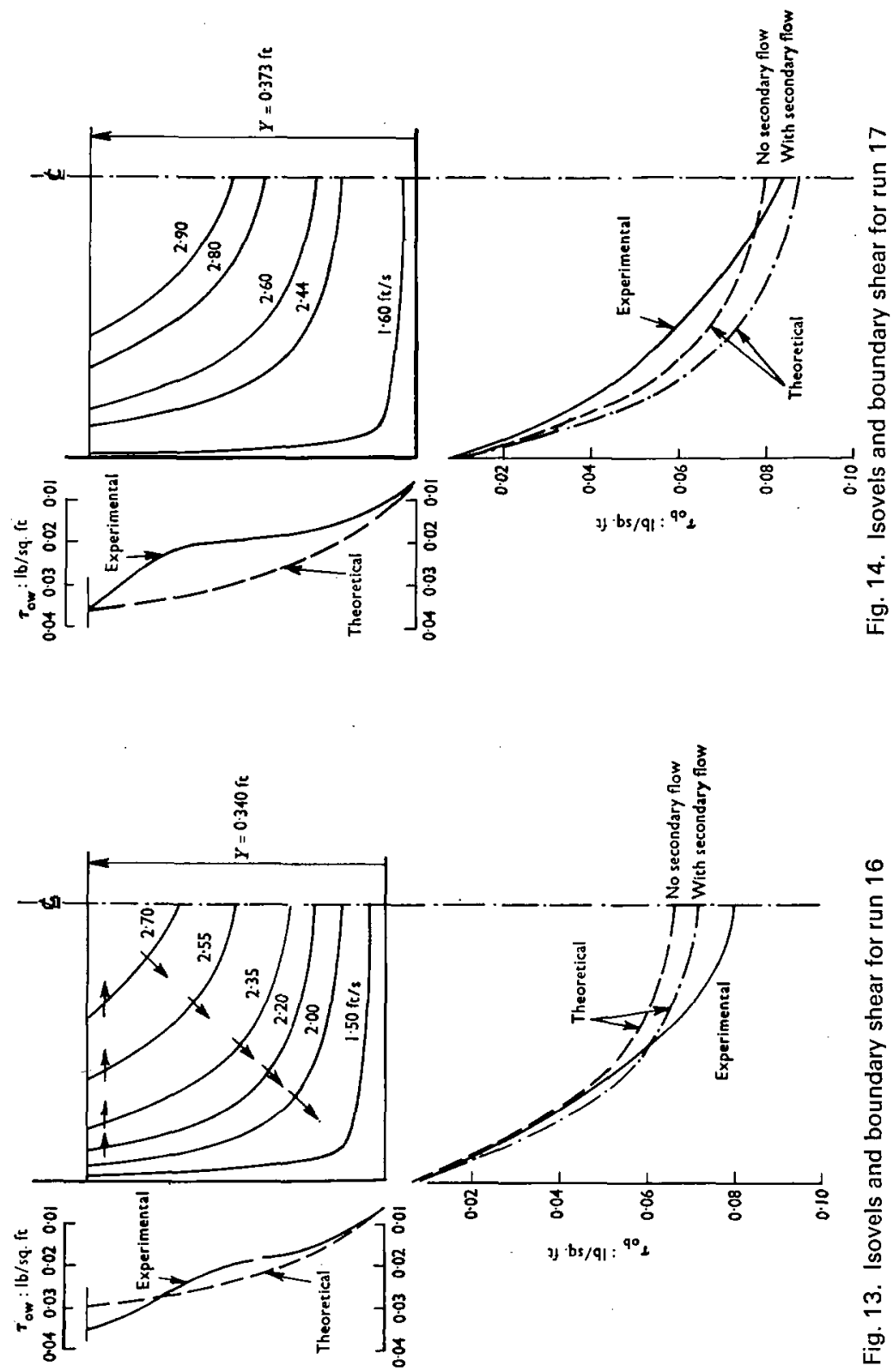

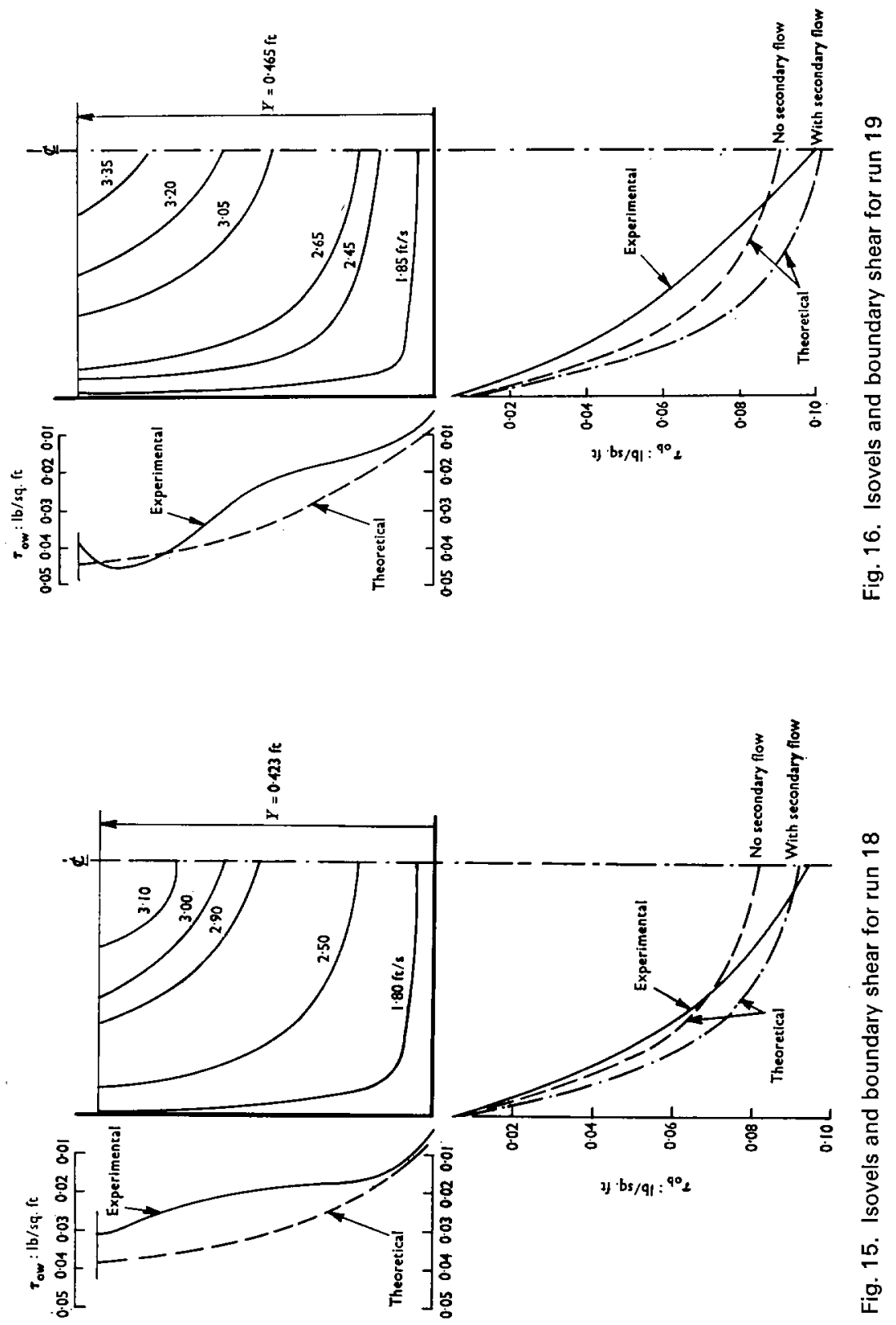

Downloaded by [] on [25/04/23]. Copyright @ ICE Publishing, all rights reserved. 


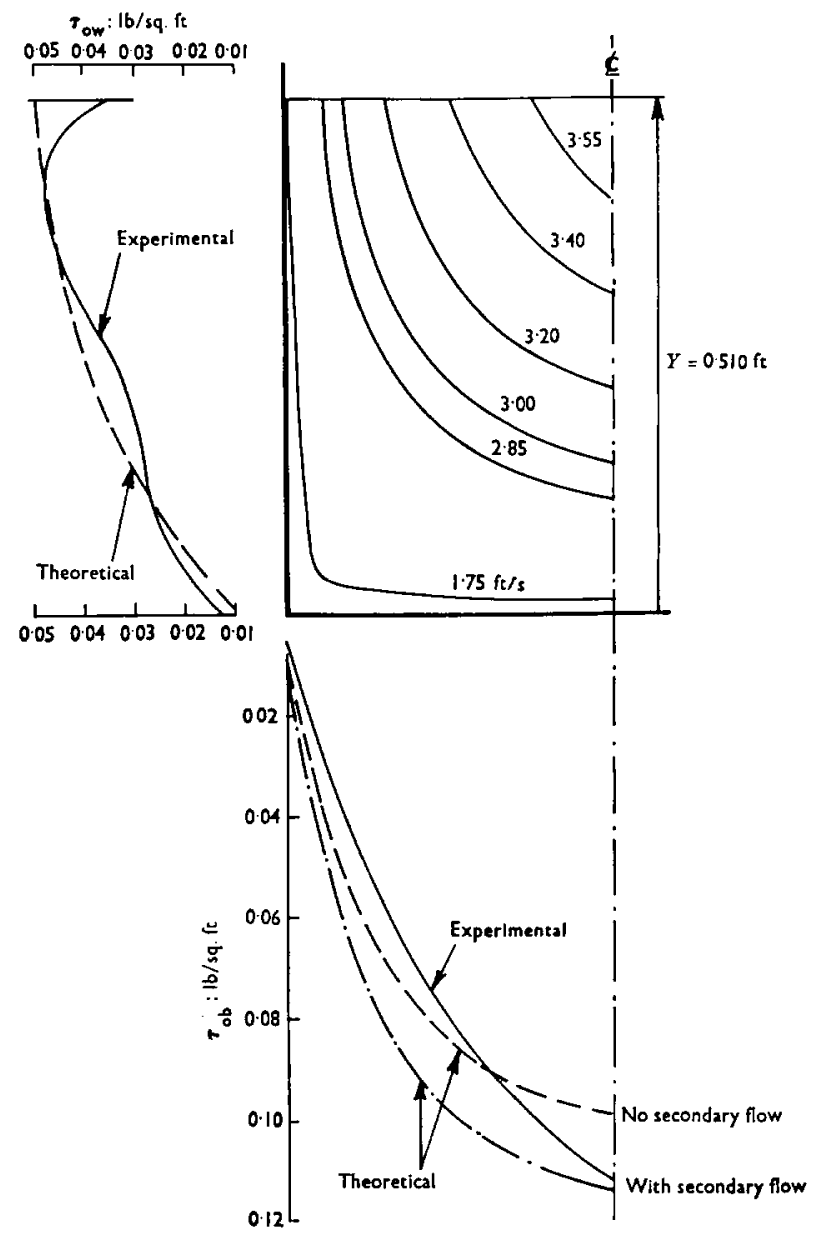

Fig. 17. Isovels and boundary shear for run 20

Table 4. Submergence of hydraulic centre $\left(y^{\prime} / Y\right)$ and percentage increase in bottom shear stresses due to secondary flows

\begin{tabular}{|c|c|c|c|c|c|}
\hline \multirow{2}{*}{ Run } & \multirow{2}{*}{$\begin{array}{c}\text { Depth } \\
Y, m\end{array}$} & \multicolumn{2}{|c|}{$y^{\prime} / Y$} & \multirow{2}{*}{$\frac{\Upsilon_{o b}^{\prime}}{\Upsilon_{o b}}$} & \multirow{2}{*}{$\underset{\%}{\text { Increase, }}$} \\
\hline & & $\begin{array}{l}\text { Theoretical } \\
\text { equation (20) }\end{array}$ & Experimental & & \\
\hline $\begin{array}{l}16 \\
17 \\
18 \\
19 \\
20\end{array}$ & $\begin{array}{l}0.340 \\
0.373 \\
0.423 \\
0.465 \\
0.510\end{array}$ & $\begin{array}{l}0.788 \\
0.755 \\
0.707 \\
0.673 \\
0.645\end{array}$ & $\begin{array}{l}0.80 \\
0.68 \\
0.72 \\
0.80 \\
0.78\end{array}$ & $\begin{array}{l}1.082 \\
1.097 \\
1.122 \\
1.141 \\
1.157\end{array}$ & $\begin{array}{r}8 \cdot 2 \\
9 \cdot 7 \\
12 \cdot 2 \\
14 \cdot 1 \\
15 \cdot 7\end{array}$ \\
\hline
\end{tabular}


in the Author's experiments is well demonstrated. The theoretical values for the bottom shear stresses were therefore adjusted according to equation (21) and are also shown in Table 3 and in Figs 13-17.

43. The shear stresses shown in Figs 13-17 agree tolerably well with the experimental values and are not only of the right order of magnitude but also correctly distributed. No doubt refinements could be made in the somewhat simple analytical approach and the agreement improved. Would the Author comment on the general theoretical approach as a means of estimating boundary shear stresses?

44. Similar equations to (18)-(19) may of course be obtained by the use of the more conventional Prandtl logarithmic law, equation (1). However, a difficulty arises in using the 'smooth' boundary velocity distribution law and the 'rough' boundary law together, and no explicit solution is possible. The case of hydrodynamically rough walls and bed is of course straightforward. It should be noted that the logarithmic law proposed by Goncharov is valid for smooth, transitional and rough boundary flow, making it eminently suitable for this type of problem.

45. Referring to Table 4, would the Author comment on why his $y^{\prime} / Y$ values did not decrease uniformly with increasing $Y$ in runs $16-20$ as would be expected from equation (20)? Does he plan to extend his experiments to cover a wider range of $B / Y$ and $Y / \Delta_{\mathrm{b}}$ values? Goncharov's experiments covered the ranges $0.87<B / Y<6.5$ and $4.7<Y / \Delta_{b}<458$ compared with the Author's ranges of $1.29<B / Y<1.93$ and $32.6<Y / A_{\mathrm{b}}<49 \cdot 0$. It would be particularly interesting to examine the effect of secondary flows.

46. Are the values of hydraulic radius given in column 4 of Table 1 correct? For the same discharge and approximately the same depth, runs 1 and 16 give values of $r$ differing by a factor of 2 . In addition the Author states in $\S 22$ that the agreement between $\left(r_{\mathrm{w}}\right)_{\mathrm{o}}$ and $\left(r_{\mathrm{w}}\right)_{\mathrm{m}}$ is good. The results presented in columns 10 and 11 of Table 1 for runs $11-15$ do not support this statement.

47. The theoretical prediction of non-uniform shear stress distribution in channels, in which the boundary roughness varies significantly over the wetted perimeter or in channels in which the cross-sectional shape is complex, is a long way from being realized, and the more experimental work undertaken with a view to solving this problem the better it will be for engineers dealing with open channel flow problems.

\section{Dr Ghosh}

On the issue of general theoretical approach in the estimation of boundary shear distribution in open channel flow, it can be said that the theoretical approach does provide an accurate picture of the pattern of the shear distribution to be expected in certain simple flow situations. Notable among the theoretical approaches for the exploration of boundary shear distribution are those by Olsen and Florey, ${ }^{18}$ Lundgren and Jonsson, ${ }^{17}$ Replogle ${ }^{6}$ and Goncharov. ${ }^{15}$ However, in most of the cases there is not complete agreement between the shear stress determined from the experimental method and that estimated analytically. Methods are based on various assumptions and so it is unlikely that complete agreement will prevail. The controversy can only be resolved if the shear stress distribution can be determined by direct measurement of drag force. Besides, in problems such as what the shear stress pattern around a bridge pier should be and over different fluvial bed configurations where the validity of wall similarity criterion is in doubt, both the analytical and the indirect method of estimation of boundary shear distribution will be ineffective, and only recourse seems to be to direct measurement using a technique such as skin friction balance, proposed by Petryk. ${ }^{18}$ In my view there is need for experimental investigation of boundary shear distribution, especially in complex flow situations so as to enable one to have a better understanding of the mechanics of local scour and sediment transport mechanism.

49. On the question of why the $y^{\prime} / Y$ values did not decrease uniformly with increasing $Y$, as expected from equation (20), it appears that Dr Knight took the $y^{\prime}$ 
values as the distance from the bed up to the mid-point of the enclosed maximum velocity contours (Fig. 4), in the computation of experimental values of $y^{\prime} / Y$. According to Goncharov, ${ }^{15} y^{\prime}$ is the height from the bed to the position of maximum velocity. A closer look at the relevant point velocity records has indicated that maximum point velocity is reached at several heights from the bed in almost all the runs, thereby creating the difficulty of choosing a particular height. By taking the mean of all the heights, I recomputed $y^{\prime} / Y$ values for runs $16-20$ and obtained the ratios as $0.77,0.75,0.75,0.73$ and 0.70 respectively, which show that in effect $y^{\prime} / Y$ decreases although not uniformly. However, this does not completely explain the question posed although it points to the fact that some errors are likely to creep in when choosing $y^{\prime}$ values. Also it appears that the location of maximum velocity will be affected by the growth and interaction of boundary layers from the side and bottom of the channel. Consequently, the likelihood of $y^{\prime} / Y$ deviating from the predicted theoretical results cannot be completely ruled out. I feel that more research is needed beyond the ranges covered by Goncharov ${ }^{15}$ and the Paper to throw more light on the effect of secondary flows on shear distribution. It would also be of interest to examine the effect of secondary flow on shear distribution in complex channel shapes resembling the river flood plain combination. To both these ends, further experimental work is in progress.

50. Dr Knight has correctly pointed out the error in the hydraulic radii values shown in column 4 of Table 1 . The values shown are associated with the smooth portion of the boundary and not overall hydraulic radii. Consequently the results shown in columns 7-10 are also in error. A summary of the correct version of columns 4 and $7-10$ is shown in Table 5. From Table 5 it can be seen that the

Table 5. Corrigendum to Table 1

\begin{tabular}{|c|c|c|c|c|c|}
\hline Run & $\begin{array}{l}\text { Hydraulic } \\
\text { radius } r, f t\end{array}$ & $\begin{array}{l}\text { Reynolds } \\
\text { number, } \\
R=U r / v\end{array}$ & $\begin{array}{l}\text { Friction factor } \\
\text { for smooth } \\
\text { boundary, } f_{\mathrm{s}}\end{array}$ & $\begin{array}{l}\text { Friction factor } \\
\text { for rough } \\
\text { boundary, } f_{\mathrm{r}}\end{array}$ & $\begin{array}{l}\text { Hydraulic } \\
\text { radius associa- } \\
\text { ted with wall } \\
\text { computed } \\
\left(r_{w}\right)_{c}, f t\end{array}$ \\
\hline $\begin{array}{l}1 \\
2 \\
3 \\
4 \\
5\end{array}$ & $\begin{array}{l}0 \cdot 173 \\
0 \cdot 182 \\
0 \cdot 192 \\
0 \cdot 200 \\
0 \cdot 208\end{array}$ & $\begin{array}{l}3.95 \times 10^{4} \\
4.46 \times 10^{4} \\
4.90 \times 10^{4} \\
5.35 \times 10^{4} \\
5.55 \times 10^{4}\end{array}$ & $\begin{array}{l}0.0192 \\
0.0189 \\
0.0182 \\
0.0180 \\
0.0175\end{array}$ & $\begin{array}{l}0.0515 \\
0.0512 \\
0.0510 \\
0.0509 \\
0.0508\end{array}$ & $\begin{array}{l}0 \cdot 312 \\
0 \cdot 310 \\
0 \cdot 330 \\
0 \cdot 336 \\
0 \cdot 383\end{array}$ \\
\hline $\begin{array}{r}6 \\
7 \\
8 \\
9 \\
10\end{array}$ & $\begin{array}{l}0 \cdot 171 \\
0 \cdot 181 \\
0 \cdot 191 \\
0 \cdot 197 \\
0 \cdot 204\end{array}$ & $\begin{array}{l}4.00 \times 10^{4} \\
4.52 \times 10^{4} \\
5 \cdot 05 \times 10^{4} \\
5 \cdot 60 \times 10^{4} \\
6.05 \times 10^{4}\end{array}$ & $\begin{array}{l}0 \cdot 0191 \\
0 \cdot 0188 \\
0 \cdot 0183 \\
0 \cdot 0180 \\
0 \cdot 0171\end{array}$ & $\begin{array}{l}0.0516 \\
0.0512 \\
0.0510 \\
0.0509 \\
0.0509\end{array}$ & $\begin{array}{l}0 \cdot 324 \\
0 \cdot 350 \\
0 \cdot 340 \\
0 \cdot 382 \\
0 \cdot 407\end{array}$ \\
\hline $\begin{array}{l}11 \\
12 \\
13 \\
14 \\
15\end{array}$ & $\begin{array}{l}0 \cdot 170 \\
0 \cdot 178 \\
0 \cdot 187 \\
0 \cdot 194 \\
0 \cdot 202\end{array}$ & $\begin{array}{l}4.02 \times 10^{4} \\
4.70 \times 10^{4} \\
5.10 \times 10^{4} \\
5.65 \times 10^{4} \\
6.35 \times 10^{4}\end{array}$ & $\begin{array}{l}0.0191 \\
0.0186 \\
0.0182 \\
0.0180 \\
0.0169\end{array}$ & $\begin{array}{l}0.0517 \\
0.0513 \\
0.0511 \\
0.0510 \\
0.0508\end{array}$ & $\begin{array}{l}0 \cdot 339 \\
0 \cdot 396 \\
0 \cdot 430 \\
0 \cdot 430 \\
0 \cdot 476\end{array}$ \\
\hline $\begin{array}{l}16 \\
17 \\
18 \\
19 \\
20\end{array}$ & $\begin{array}{l}0 \cdot 167 \\
0 \cdot 172 \\
0 \cdot 184 \\
0 \cdot 192 \\
0 \cdot 200\end{array}$ & $\begin{array}{l}4.11 \times 10^{4} \\
4.80 \times 10^{4} \\
5.00 \times 10^{4} \\
5.78 \times 10^{4} \\
6.40 \times 10^{4}\end{array}$ & $\begin{array}{l}0.0191 \\
0.0186 \\
0.0183 \\
0.0180 \\
0.0169\end{array}$ & $\begin{array}{l}0.0517 \\
0.0516 \\
0.0511 \\
0.0510 \\
0.0509\end{array}$ & $\begin{array}{l}0.099 \\
0.120 \\
0 \cdot 116 \\
0 \cdot 121 \\
0.127\end{array}$ \\
\hline
\end{tabular}


$\left(r_{\mathrm{w}}\right)_{\mathrm{o}}$ values for runs 1-15 are consistently higher than $\left(r_{\mathrm{w}}\right)_{\mathrm{m}}$ shown in Table 1 , and they seem to be related by a simple relationship, $\left(r_{\mathrm{w}}\right)_{\mathrm{c}}=1 \cdot 3\left(r_{\mathrm{w}}\right)_{\mathrm{m}}$. This is not entirely unexpected considering the amount of simplification involved in the analysis of a complex phenomenon. Nevertheless, the main purpose of the exercise is to explore the possibility of realizing a simple relationship which can be applied to separate wall effect in an essentially three-dimensional complex flow, and it can be said that such an objective has at least partially been achieved.

\section{References}

14. WAGNER H. Laminar flow in open rectangular channels. In Proceedings of the thirteenth congress of the International Association of Hydraulic Research, Kyoto, 1969, 1.

15. Goncharov V. N. Dynamics of open channel flow. Israel Program for Scientific Translations, Jerusalem, 1964.

16. Olsen O. J. and Florey Q. L. (compilers). Sedimentation studies in open channels: boundary shear and velocity distribution by membrane analogy, analytical and finite difference methods. Reviewed by D. McHenry and R. E. Glover. U.S.B.R. Laboratory Report Sp 34, 1952.

17. LUNDGREN H. and Jonsson J. Shear and velocity distribution in shallow channels. J. Hydraul. Div. Am. Soc. Civ. Engrs, 1964, 90, HY 1, Jan., 1-21.

18. Petryk S. and Shen H. W. Direct measurement of shear stress in a flume. J. Hydraul. Div. Am. Soc. Civ. Engrs, 1971, 97, HY 6, June, 883-887. 